Macedonian Pharmaceutical Bulletin, 66 (Suppl 1) 155 - 156 (2020)

Online ISSN 1857 - 8969

UDC: 005.963 .1

DOI: 10.33320/maced.pharm.bull.2020.66.03.077

Short communication

\title{
Competency-based training system
}

\author{
Mena Ivanoska Zdravkovska*, Silvija Saveska, Dafinka Damcevska, \\ Blagica Samarova Stoev, Tatjana Bogovska, Nada Stojanoska, \\ Milena Dobrkovic Shotarovska, Marina Mandzukovska Micevska, Hristina Babunovska
}

\begin{abstract}
Alkaloid AD-Skopje, Pharmaceutical, Chemical and Cosmetics Industry, blvd. Aleksandar Makedonski 12, 1000 Skopje, Republic of Macedonia
\end{abstract}

\section{Introduction}

For years many companies electronically tracked employee training and provided exams to determine that an employee was qualified to do the assigned job. A new requirement for the organizations is to establish a process for assessing existing staff competencies under its control.

\section{Regulatory background}

A review of the most widely reference ISO standards reveal the need for competent staff and assessment of their competence. All clauses requires organizations shall determine the necessary competence, provide training or take actions to satisfy competency gaps, evaluate the effectiveness of the actions taken, maintain records of education, training, skills and experience and retain appropriate documentation as evidence of competence.

\section{Competency-Based Training Programs}

The competency-based programs will vary greatly and are unique to the product being manufactured or services provided. The type of product manufactured or services provided, and the level of education, training, and experience of the personnel determine the elements of a competencybased training program. To establish and maintain a competency-based training program, the following steps must be taken:

1. Identify competency-based training requirements and needs;

2. Deliver training content;

3. Evaluate the effectiveness of training.

Training is provided for many reasons. Typically, a company performs training due to improving employee skills, compliance requirements, safety issues, changes to processes, quality improvements, and so on. Training alone is not enough to demonstrate competence; this must be demonstrated through tests, observations, and assessments. Should be provided objective evidence in order to determine that the competency requirements have been met. The questions that need to be answered are the following:

- Are records maintained and periodically reviewed?

- How does your organization determine the necessary skills and competence of person(s) doing work under its control that affect its QMS?

- Are training matrixes periodically reviewed for updates? Is this documented?

- What type of assessments do you use to evaluate competence?

- How and when do you perform assessments?

- What actions are taken when training is deemed ineffective?

\footnotetext{
*mivanoska1@alkaloid.com.mk
} 
-What actions do you take when an employee is not competent to perform the tasks assigned?

Identify competency-based training requirements and needs

Organizations should establish a process for assessing existing staff competencies against changing business needs and prevailing trends. The first step is to identify which competencies are needed in line with the stated job functions. These competencies should be supported by training, education, and experience. To expand on this, the organizational matrix must be built for each position which is tied back to the approved job description. Starting with the job description the organization should identify the education level, type of education, and experience. Documented proof that the individual has the education and experience must be captured and available. The next step is to build a matrix comparing a specific job to the actual training requirements and the competence level required of each training requirement. The types of training should include:

- New employee orientation (company and department)

- Department-specific training

- Job-specific technical training

- Work-area-specific training (safety, SOP, etc.)

- Industry-specific ISO and regulatory training

- Supervisory training

\section{Evaluate the effectiveness of training}

What is important is the evaluation of training effectiveness and ongoing evaluation of how competent the employees are performing their duties. By performing such evaluations, the organization will be able to determine if additional training is required to achieve competency, the quality of the training material, or if staff should be reassigned due to inability to achieve competency.

The following are standard ways to assess training:

- Take a test at the beginning and end of training

- Evaluate in a real time situation with a subject matter expert (SME)

- Prepare self-assessment

- Feedback from the team or coworkers

- Manager assessment
- Customer assessment

The above process will give you what is known as a 360-degree assessment. This will yield the most accurate results because it rates the individual as objectively as possible from every angle. Once all assessments have been completed, the average of the scores are taken to find the competence score. After the assessments have been completed, the individual's competence is determined, gaps identified, and a new training path determined.

\section{In summary}

Once an organization has identified all the training requirements and the level of competency for each requirement, these requirements and competency levels are assigned to individual employees. These requirements and competencies are compared against the training and competency each employee has completed. The gap between required training competence and completed training defines what additional training is required of the employee. Training alone does not determine competence. The effectiveness of the training must be evaluated and the competence of the individuals through skill checks and evaluations.

\section{Acknowledgement}

The author would like to thank Alkaloid ADSkopje, Pharmaceutical, Chemical and Cosmetics Company, for support, comments and suggestions made during the writing of this paper.

\section{References}

EudraLex, The Rules Governing Medicinal Products in the European Union, 2014. Volume 4 EU Guidelines for Good Manufacturing Practice for Medicinal Products for Human and Veterinary Use, Part 1 Chapter 2: Personnel.

ISO 9001:2015(en) Quality management systems Requirements.

https://pathwise.com/.

Maced. Pharm. Bull. 66 (Suppl 1) 155 - 156 (2020) 